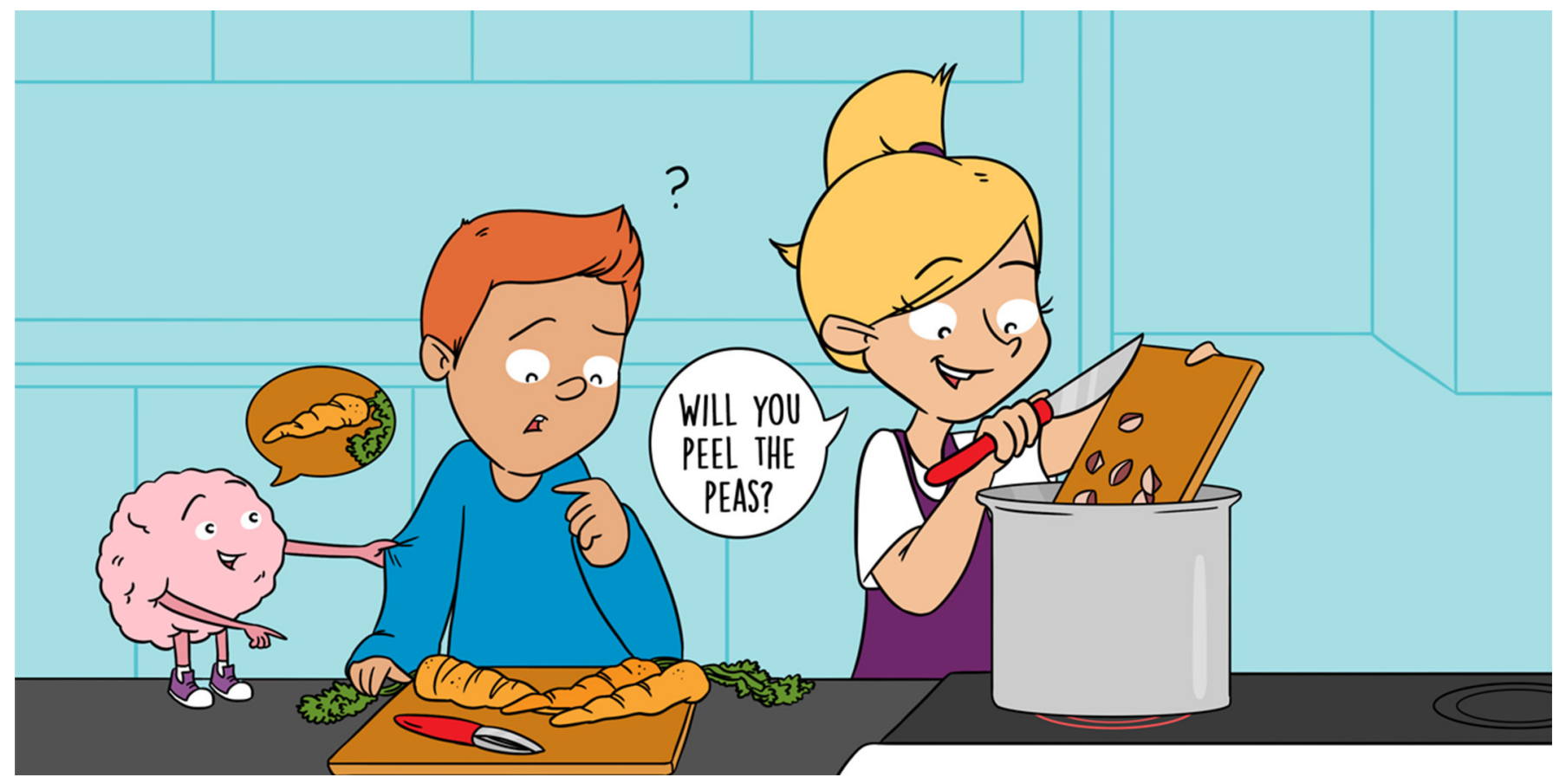

\title{
SOMETIMES WE DO NOT HEAR WHAT PEOPLE SAY, INSTEAD WE HEAR WHAT WE EXPECT THEM TO SAY
}

\section{Nikole D. Patson *}

Department of Psychology, Ohio State University at Marion, Marion, OH, United States

YOUNG REVIEWERS: DILWORTH MIDDLE SCHOOL AGES: 11-14
Sometimes people make mistakes when they are speaking. For example, someone might say, "Can you hand me the hammer?" when they meant to ask for a screwdriver. Because this mistake is related to the meaning, it is called a semantic error. Sometimes listeners (or readers) notice these errors and sometimes they do not. Language scientists are interested in how people's brains respond when sentences have semantic errors. To study this, scientists have done experiments using a technique called EEG. These experiments have shown that people's brains respond differently to different kinds of semantic errors. In particular, there is a certain brain response based on how well the incorrect word fits in with the other words in the sentence. These experiments have shown that our brains often use knowledge about what kinds of words are expected in a sentence to construct meaning from that sentence.

\section{INTRODUCTION}

Last week, my friend and I were in my kitchen cooking together. She was standing next to a pile of unpeeled carrots, and she asked if 


\section{SEMANTICS}

The meaning of words and sentences. In linguistics, semantics often refers to the study of the meaning of language.

\section{SEMANTIC}

\section{ANOMALY}

A word in a sentence that is unexpected given the other words in the sentence. For example, I take my coffee with cream and dogs. she could do something to help. "Oh, since you are standing there, you could peel the peas," I said. I noticed my mistake, but when she heard "peel" she had already started reaching for the carrots, and she did not even notice that I had said "peas" instead of "carrots"! Compare that with the time when I was in third grade and I went up to my teacher and asked, "Mom, can I go to the bathroom?" Much to my embarrassment, I think the whole class heard my mistake and everyone started laughing!

Language scientists are often interested in these kinds of mistakes and whether or not people notice them. In both cases, the mistake I made was a semantic error. Semantics refers to the meaning of language. Consider this famous sentence written by the linguist Noam Chomsky: "Colorless green ideas sleep furiously." Would you agree that the words are all in the right place in the sentence? And yet, the sentence does not make any sense. That is because some of the words are combined in a way that does not quite work. For example, it is not possible for something to be both green and colorless. Noam Chomsky came up with this sentence to make exactly this point: sometimes words can be in the right place in a sentence, but the sentence still does not make sense, because the words are combined in a way that is not meaningful.

Similar to the examples provided above, language scientists have discovered that some semantic errors (also called semantic anomalies) are easier to notice than others. Language scientists study how people react to different kinds of language mistakes, because it can tell us something about how the brain constructs meaning from the words it is reading or hearing. Scientists want to understand what determines whether or not someone notices a semantic anomaly.

\section{DIFFERENT KINDS OF SEMANTIC ANOMALIES}

Let us start with a puzzle. Imagine this scenario: An airplane has just crashed on the border of Spain and France. The plane debris is scattered throughout both countries. Importantly, none of the passengers are from either Spain or France. Where should authorities bury the survivors?

What do you think? Where should they be buried? If you have selected a burial location, you have made a mistake! Go back and reread the scenario. Do you see the problem? The question asks you where to bury the survivors! However, survivors are ALIVE, so you should not bury them!

Do not worry, if you got tricked, you are in good company. Language scientists have given this same scenario to lots of volunteers in many experiments [1]. They have found that, most of the time, those 
volunteers also do not notice that you should not bury survivors. Why do not people notice the mistake in the question? Let us change up the scenario a bit. Imagine that the scenario was about a bike accident rather than a plane crash: A bicycle crash has just occurred on the border of Spain and France. Bicycle debris is scattered throughout both countries. Importantly, none of the riders are from either Spain or France. Where should authorities bury the survivors? Do you think you would have been tricked if you had read this story instead of the story about the plane crash? If you said "no," you are right! In fact, when scientists asked volunteers to read this version of the story, almost no one was tricked.

Why do people notice that survivors should not be buried when the story is about a bike crash but not a plane crash? One important difference between the two stories is how well the word "survivor" fits into the scenario. When a plane crashes, it is usually an extremely devastating event, so people are very likely to talk about whether or not there are any survivors. However, when there is a bicycle crash, it is unlikely to be as devastating. The people on the bikes might be hurt, but they are unlikely to be killed. So, in the case of a bicycle crash, people are very unlikely to talk about survivors. One idea about what is happening when people do not notice semantic anomalies is that, when a word fits well into the story, the brain might not fully interpret what the word means. For example, the word survivor means "a person who is still alive." In stories where we expect to hear about survivors, the brain might activate only the idea of "person" and not "who is still alive." This is just one of the ways that the brain can be a bit lazy when interpreting language [2].

ELECTROENCE-

PHALOGRAM (EEG)

Measurement of the electrical activity of many neurons in the brain, using electrodes placed on the scalp.

EVENT RELATED POTENTIAL (ERP)

Peaks or troughs in the averaged EEG signal that reflect the brain's responses to events we see or hear.

\section{WHAT HAPPENS IN THE BRAIN DURING SEMANTIC ANOMALIES?}

After decades of research, language scientists have found that people's brains respond differently to different kinds of errors in a sentence. One way to study the brain's response to semantic errors is to use electroencephalogram (EEG). EEG measures the electrical activity that is always happening in every part of the brain. To measure this activity, scientists ask people to wear special caps that are covered with sensors called electrodes. The electrodes sit on the scalp and measure the electrical activity coming from the neurons (brain cells) that are right underneath the electrodes. Scientists can then study how the electrical activity changes based on what volunteers are doing.

Scientists have recorded EEG's while volunteers read sentences with semantic anomalies. In their experiments, scientists asked volunteers to read many sentences that contain semantic mistakes. The scientists then and take the average of the brain's activity when as the volunteers read the sentences. The averaged brain activity is called an event-related potential (ERP) waveform, which that is like a wave that contains several high and low points. Those high and low 


\section{Figure 1}

The type of semantic anomaly can affect the brain's N400 response.

\section{N400 ERP}

\section{COMPONENT}

A part of the ERP that typically has a low point around $400 \mathrm{~ms}$ (therefore "400") after a person sees or hears a stimulus. In language studies, the N400 is larger when a word is unexpected.

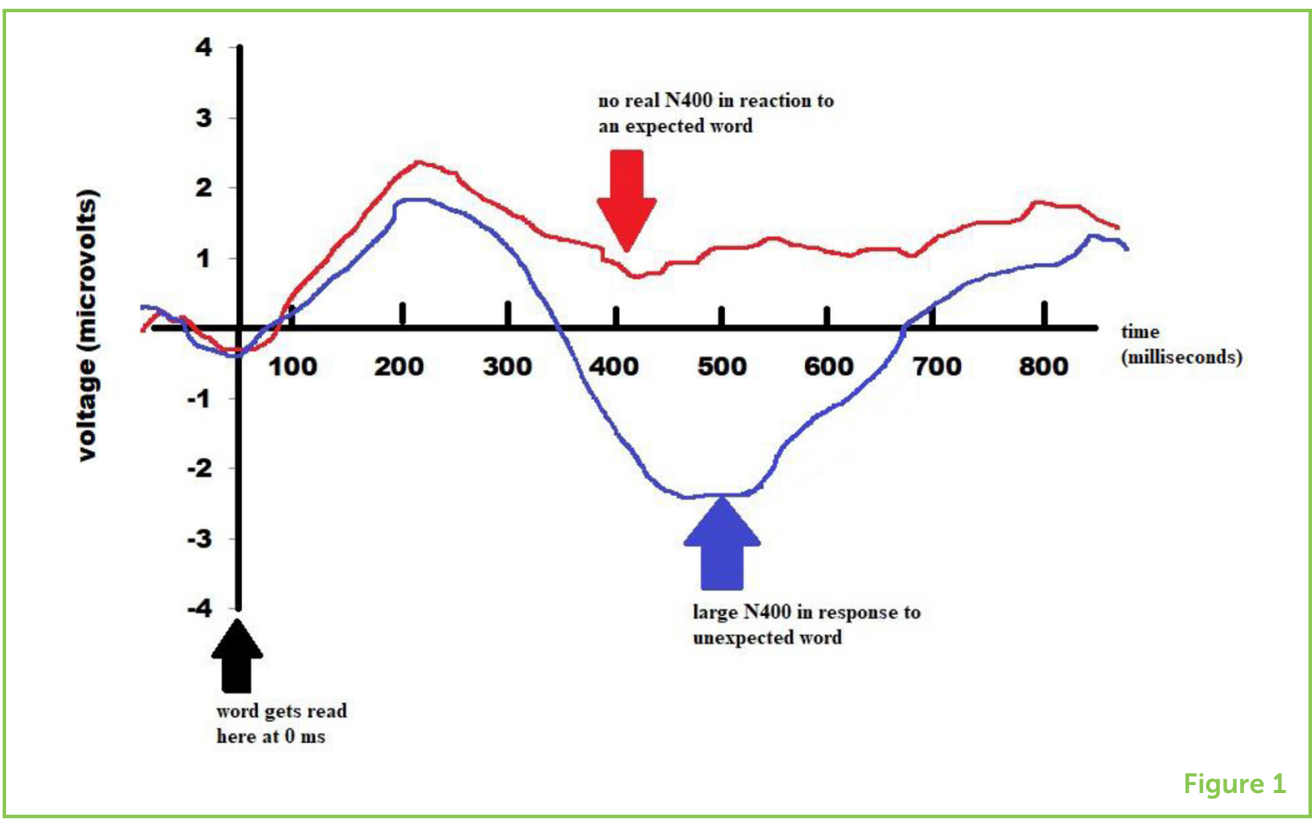

points represent the brain's response to the sentence over time. After decades of research, scientists have learned that there are predictable patterns of high and low points in the ERP, and. When that is the case, those high and low points are were given names. For example, a low point that occurs around 400 milliseconds (ms; 1/1,000 of a second) after an unexpected word appears is known as an N400 ERP component (this is just one of the many types of stimuli that cause an N400 [3]). The size of the ERP components (measured in voltage) reflects how strong the brain's response is, while the timing of these ERP components (measured in milliseconds after the stimulus) reflects the timing of the response.

Language scientists have found that the size of the N400 ERP component depends on the kind of semantic anomaly that is in the sentence. Some semantic anomalies are very easy to notice. For example, everyone notices the mistake in the sentence: "I take my coffee with cream and dogs." Scientists have found that, when volunteers read these kinds of anomalies, their brains show a large N400 component after reading the incorrect word. However, when volunteers read sentences with hard-to-detect anomalies (like the plane crash/survivors example above) their brains do NOT show a large N400 component when they read the incorrect word (Figure 1) [4].

When an anomaly is expected because the word fits into the scenario ("the eggs ate the toast"), or if there is no anomaly at all, the brain does not show a large N400 effect. This can be seen by the red line. However, when the anomaly is unexpected ("coffee with cream and dogs"), the brain shows a large N400 effect. This can be seen by the blue line. 
This experiment shows that we can expect an N400 when a semantic anomaly is easy to notice, but not when it is difficult to notice. However, if that were the only kind of difference the N400 could detect, it would not be useful to scientists. Instead of doing an expensive brain study, scientists could just ask volunteers whether or not they noticed the anomaly and find the same results! Importantly, language scientists have also found that peoples' brains do not always show a large N400 component when they read easy-to-detect semantic anomalies. For example, when people read sentences like, "At breakfast, the eggs ate the toast," their brains do not show a large N400 response on the word "toast," even though they notice the anomaly in the sentence. If we compare these two easy-to-detect anomalies, we can get an idea about what is going on in the brain. In the "cream and dogs" example, "dogs" does not fit into the scenario being described in the sentence. However, in the "eggs ate the toast" example, the scenario is about breakfast, and both eggs and toast are things people might say when talking about breakfast. What scientists have decided is that the N400 is larger when a word does not fit well into the scenario being described in the sentence. If a word fits well into the scenario, even if the word does not really make sense, people's brains do not show a large N400 and, if you ask them, they might not have even noticed the mistake.

\section{WHY IS IT IMPORTANT TO STUDY SEMANTIC ANOMALIES?}

The study of how people's brains react to semantic anomalies helps language scientists understand how the brain builds meaning from words and sentences. These studies suggest that the brain often uses a "top-down" approach to understand language rather than a "bottom-up" approach. A bottom-up approach would mean that the brain builds the meaning of a sentence by fully understanding the meaning of each word as we read or hear it. If the brain used a bottom-up approach, more people should notice semantic anomalies. That is, they should notice that you should not bury survivors, because they would activate the full meaning of the word "survivors," which includes the fact that the people are still alive.

Using a top-down approach, the brain uses background knowledge to process the meaning of a sentence, based on how expected a word is in that scenario. When a word is expected because it fits well, the brain might be a bit lazy when determining the meaning of that word. For example, the word "survivor" means "a person who is still alive." In stories where we expect to hear about survivors, the brain might just activate "person" and not activate the rest of the meaning. Understanding how people use both top-down and bottom-up approaches to make meaning from language is useful for doctors who treat patients who have language disorders. 
Although we have clearly seen the importance of the N400 in understanding how the brain responds to different kinds of semantic anomalies, scientists are still trying to figure out exactly what the N400 tells us the brain is doing [5]. One idea is that the brain makes predictions about what words it will see, and the N400 is large when a word is unexpected. A different idea is that the brain is simply checking words as they come in to make sure they fit into the sentence, and a large N400 reflects that a word does not fit. Either way, these EEG studies have taught us that sometimes what we see or hear is what our brain expects to see or hear!

\section{REFERENCES}

1. Sanford, A. J., and Sturt, P. 2002. Depth of processing in language comprehension: not noticing the evidence. Trends Cogn. Sci. 6:382-6. doi: 10.1016/s1364-6613(02)01958-7

2. Ferreira, F., and Patson, N. D. 2007. The 'good enough' approach to language comprehension. Lang. Linguist. Compass 1:71-83. doi: 10.1111/j.1749-818x.2007.00007.x

3. Kutas, M., and Federmeier, K. D. 2011. Thirty years and counting: finding meaning in the $\mathrm{N} 400$ component of the event-related brain potential (ERP). Annu. Rev. Psychol. 62:621-47. doi: 10.1146/annurev.psych.093008.131123

4. Sanford, A. J., Leuthold, H., Bohan, J., and Sanford, A. J. 2011. Anomalies at the borderline of awareness: an ERP study. J. Cogn. Neurosci. 23:514-23. doi: $10.1162 /$ jocn.2009.21370

5. Lau, E. F., Phillips, C., and Poeppel, D. 2008. A cortical network for semantics: (de) constructing the N400. Nat. Rev. Neurosci. 9:920. doi: 10.1038/nrn2532

SUBMITTED: 23 August 2019; ACCEPTED: 05 March 2020; PUBLISHED ONLINE: 27 March 2020.

EDITED BY: Gideon Paul Caplovitz, University of Nevada, Reno, United States

CITATION: Patson ND (2020) Sometimes We Do Not Hear What People Say, Instead We Hear What We Expect Them to Say. Front. Young Minds 8:34. doi: 10. 3389/frym.2020.00034

CONFLICT OF INTEREST: The author declares that the research was conducted in the absence of any commercial or financial relationships that could be construed as a potential conflict of interest.

COPYRIGHT () 2020 Patson. This is an open-access article distributed under the terms of the Creative Commons Attribution License (CC BY). The use, distribution or reproduction in other forums is permitted, provided the original author(s) and the copyright owner(s) are credited and that the original publication in this journal is cited, in accordance with accepted academic practice. No use, distribution or reproduction is permitted which does not comply with these terms. 


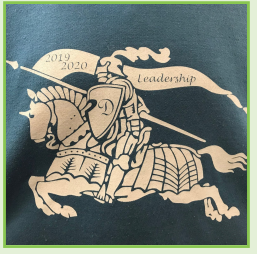

\section{YOUNG REVIEWERS}

\section{DILWORTH MIDDLE SCHOOL, AGES: 11-14}

This paper was reviewed by Ms. Scull's Leadership Class of sixth, seventh, and eighth grade students at Dilworth Middle School in Sparks, Nevada. The students found this article engaging and were interested that such an everyday occurrence as mis-speaking could be used in scientific research.

\section{AUTHOR}

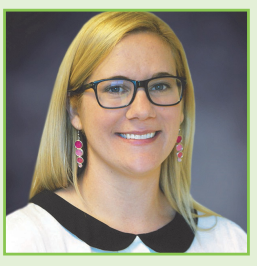

\section{NIKOLE D. PATSON}

I am an Associate Professor at Ohio State University in Marion where I teach courses in Cognitive Psychology and conduct research on how adults understand meaning from language. I received my Ph.D. from the University of Pittsburgh in 2011, where I studied the kinds of meaning adults create when reading about plurals. I now conduct much of my research at the Language Sciences Research laboratory at the Center for Science and Industry (COSI) in Columbus, OH. At the Language Sciences lab, I get to trick people with semantic anomalies using a popular demonstration I created. *patson.3@osu.edu 